The Impact of Negative Symptoms and Self-Criticism on the Urge to SelfInjure

\author{
Alfath Hanifah Megawatia, Cantyo Attindriyo Dannisworo ${ }^{\mathrm{b}}$, and Lathifah \\ Hanum $^{c}$
}

$a_{\text {Faculty of Psychology, Universitas Indonesia, Depok, Indonesia; }}{ }^{b}$ Department of Clinical Psychology, Faculty of Psychology, Universitas Indonesia, Depok, Indonesia; ${ }^{c}$ Department of Clinical Psychology, Faculty of Psychology, Universitas Indonesia, Depok, Indonesia

*Corresponding author:

Cantyo Attindriyo Dannisworo

Department of Clinical Psychology

Faculty of Psychology, Universitas Indonesia

Jl. Lkr. Kampus Raya, Depok, Jawa Barat

Indonesia, 16424

Tel.: +62 217270004

Email address: cantyo.dannis@ ui.ac.id / cantyo.dannis@gmail.com 


\title{
The Impact of Negative Symptoms and Self-Criticism on the Urge to Self- Injure
}

\begin{abstract}
Stressful life events brought on by the demands of academic and social life are possibly a factor engendering various negative emotional symptoms, such as depression, anxiety, and stress, in college students. Furthermore, failure to obtain positive feedback may possibly provoke self-criticism in them. These conditions, if not handled properly, will develop maladaptive behavior. Previous studies have found that negative emotional symptoms and self-criticism correlate with self-injury. However, these studies did not explain the impact of variables on self-injury. This study aims to find out how the impact of negative emotional symptoms and selfcriticism acts on the urge to self-injure. It was a cross-sectional study populated by 118 college students with the following criteria: aged 18-30 years old, having engaged in self-injury at least once in the past year, having undiagnosed clinical disorders, and not currently undergoing psychotherapy. The result revealed that negative emotional symptoms and self-criticism, as predictors, had a strong correlation $(\mathrm{r}=0.744, \mathrm{p}=0.000)$. Furthermore, both predictors had a moderate correlation with the urge to self-injury $(\mathrm{r}>0.400, \mathrm{p}=0.000)$ and simultaneously impacted on the urge to self-injure by 32 percent $\left(R=0.564, R^{2}=0.318\right.$, Std $=$ $5.209, \mathrm{p}=0.000)$. According to these results, negative emotional symptoms and selfcriticism tendencies were significant factors that contributed to psychological vulnerability in college students. The higher the level of negative emotional symptoms and self-criticism, the higher the urge to self-injure in college students. These findings supported the idea that self-injury is an emotional coping mechanism to release psychological distress. Self-injury is a student's attempt to escape from the pain due to unbearable psychological stress. The high contribution of these variables makes them an issue that must be considered in interventions to deal with self-injury.
\end{abstract}

Keywords: college student, negative emotion, self-criticism, self-injury, student, non-suicidal self-injury

\section{Introduction}

Self-injury is a focus of research and intervention in various countries because of the physical and psychological consequences of this behavior, especially in young people (Carvalho et al., 2015; Glassman et al., 2007). Some studies found that the prevalence of this behavior increased every year (Hankin \& Abela, 2011; Hoff \& Muehlenkamp, 2009; Hooley \& St. Germain, 2013; Jacobson \& Gould, 2007; Nock, 2010; Williams \& Bydalek, 2007) and the rate of increase had been higher in recent years (Carvalho et al., 2015). Self-injury is an act of intentionally hurting oneself without the intention of suicide (Klonsky, 2009; Muehlenkamp, 2005), and not socially sanctioned (Suyemoto, 1998). This behavior is also known as nonsuicidal self-injury, moderate self-mutilation, deliberate self-harm, self-wounding, and parasuicide (Klonsky, 2007). Klonsky (2007) classifies several methods of self-injury, such as burning, scratching, banging or hitting body parts, interfering with wound healing, and deliberately ingesting harmful toxic chemicals. 
The early onset of this behavior was consistently at the age range of 12-16 years (Klonsky, Muehlenkamp, Lewis, \& Walsh, 2011), but the high prevalence of self-injury behavior is mainly found in late adolescence through to 30 years of age (Hooley \& St. Germain, 2013; Klonksy, 2011). Furthermore, self-injury behavior did not only occur in the clinical population but also in non-clinical populations with a prevalence of $4 \%-6 \%$ in adults (Klonsky, 2011; St. Germain \& Hooley, 2012) and 14\% - 35\% in college students (Whitlock, Eckenrode, \& Silverman, 2006). The high prevalence of this behavior makes self-injury a phenomenon that attracts the attention of many researchers in conducting further studies, especially among college students.

In line with their age, college students are in a transition period from late adolescence to early adulthood, commonly termed "emerging adulthood". In this period, many aspects of transitional social life that are faced by college students, such as leaving home, completing high-level education, and committing to romantic relationships (Arnett, 2007). In this period, individuals begin to develop separated identity from their parents (Gilbert \& Irons, 2009; Wolfe \& Mash, 2006). Transitional events and independence from parental figures suggest that individuals should explore the various possible directions of aspects in their life (Arnett, Kloep, Hendry, \& Tanner, 2011). On the other hand, individuals also develop needs to meet the expected personal standards of significant people in their lives, such as parents, a romantic partner, friends, or teachers (Hewitt, Newton, Flett, \& Callander, 1997). Besides being expected to achieve in the academic setting and socially, college students must be able to adjust to their new environment and establish wider social relations. These demands become a stressor that triggers various negative emotional symptoms, such as depression, anxiety, and acute stress. Several studies have tried to explore the relationship between negative emotional symptoms and self-injury behavior. The results showed that negative emotional symptoms were found to be significantly associated with self-injury behavior (Izadinia, Amiri, Jahromi, \& Hamidi, 2010; Klonsky \& Glenn, 2009; O’Connor, Rasmussen, \& Hawton, 2010; Raza, Abbasi, Khurshid, \& Ansari, 2018; Whitlock \& Knox, 2007).

Negative emotional symptoms, such as depression and anxiety, were found to be associated with critical self-perception or rating one's own abilities lower than others' (Gilbert, 2000). This negative self-perception makes individuals vulnerable to internalizing feelings of shame about themselves, feelings of inadequacy or doubt about themselves, to develop hostility toward themselves, and push themselves too hard, all are aspects of what is termed selfcriticism (Gilbert, 1998; Van Vliet \& Kalnins, 2011; Xavier, Gouveia, \& Cunha, 2016). In college students themselves, self-criticism may increase when they experience difficult situations or failure in important life tasks (Gilbert, Clarke, Hempel, Miles, \& Irons, 2004; Xavier, Cunha, \& Pinto-Gouveia, 2015), for example, in academic matters and love. Selfcriticism involves an automatic response to blame or attack oneself with anger, shame, or self-hatred (Xavier, Cunha, \& Pinto-Gouveia, 2015). In other words, self-criticism becomes increasingly likely to be develop when individuals experience negative emotional symptoms (Gilbert, 2000). 
Self-criticism is also considered as a potential factor that formed in early individual development because of a maltreatment experience (Gilbert, 1998; Gilbert, Clark, Hempel, Miles, \& Irons, 2004). Self-criticism is another factor that is widely studied and found to be directly related to self-injury (Hooley \& St Germain, 2014; Van Vliet \& Kalnins, 2011). Those who practiced self-injury reported that this behavior helped them to vent their feelings of anger, shame, and self-hatred (Favazza, DeRosear, \& Conterio, 1989; Himber, 1994; Connor, 1996). The individuals assume that the self-injury behavior can purify that part of themselves that they hate and shift their attention from them (Connor, 1996; Himber, 1994; Shearer, 1994; Zlotnick, Donaldson, Spirito, \& Pearlstein, 1997).

This explanation is also put forward by escape-style-coping theory (Baumeister, 1990; 1991; Nock \& Prinstein, 2004; Williams, 2010). This theory proposed that suicidal behavior and self-injury occur because individuals are not able to perceive their failures. This condition is followed by increased distress conditions, such as depression, anxiety, and stress. When psychological distress becomes excessive, the individual's ability to solve the problem will be disrupted, which leads to maladaptive behavior as the only possible way seen to eliminate unbearable distress (Hoff \& Muehlenkamp, 2009; Muehlenkamp \& Gutierrez, 2004; Ross \& Heath, 2002). Thus, self-injury behavior is one maladaptive emotional coping strategy to reduce psychological distress (Nock \& Prinstein, 2004; Purington \& Whitlock, 2010). Individuals hope that this behavior can shift or free them from the uncomfortable state due to being overwhelmed by distress (Walsh, 2007).

Some scientific studies have found that the main purpose of self-injury behavior is not only to regulate negative emotions, but also to punish oneself, feel physical sensations, and influence one's social environment, by attention-seeking or appeasement (Gratz \& Chapman, 2009; Nixon \& Cloutier, 2005; Nock, 2009; Xavier, Cunha, \& Pinto-Gouveia, 2015). Hooley and St. Germain (2013) found that this also happened to individuals who had the idea or the urge to hurt themselves but had not actually done so. The higher the psychological distress experienced by the individuals, the higher the tendency for the urge to self-injure behavior tp emerge (Izadinia, Amiri, Jahromi, \& Hamidi, 2010; Richmond, Hasking, \& Meaney, 2017).

In Indonesia, what is known about self-injury behavior is the tip of the iceberg, and there are not many studies on it directly in the college student population. In addition, many previous studies only focused on patients in the clinical population. These limitations are the reasons why the current study is important. The discovery of predictors of self-injury in non-clinical populations can anticipate the development of this behavior into clinically mental disorders. College students are individuals who are expected to be the next generation's leader, thus maintaining their mental health is very important. Therefore, this study aims to determine the impact of negative emotional symptoms and self-criticism on the urge to self-injure among college students. The hypothesis of this study is that both negative emotional symptoms and self-criticism, have a significant influence on the intensity of the urge to self-injure in college students. 


\section{Method}

This study was conducted on a non-clinical population. The participants in this study had never received a diagnosis of mental disorders, did not take medications for psychological disorders, were not undergoing psychotherapy, and had a status as an active student. Other specific criteria of participants in the current study were that they were between 18 and 30 years old, currently living in Jakarta-Bogor-Depok-Tangerang-Bekasi (Jabodetabek), and self-injuring in the past year. From 126 people who filled out the online questionnaire, 118 met the criteria and filled out the questionnaire completely. 83 percent of participants in this study were women $(n=98, M=17.95)$, the other 17 percent were men $(n=20, M=18.20)$. The current study had been through ethical clearance review by a team from the Faculty of Psychology, Universitas Indonesia.

\section{Measures}

There were three main variables in this current study: negative emotional symptoms, selfcriticism, and the urge to self-injure. All measures used in this study were psychometrically tested with youth samples. The data of these variables were processed statistically by two methods using SPSS 21. The first method was a bivariate correlation test, to find the correlation among variables. The second method was linear multiple regression analysis, to find the coefficient of the impact of the predictors. Other data were processed by descriptive analysis.

Negative Emotional Symptoms. This variable was measured by Depression Anxiety and Stress Scales (DASS-21), which was developed in 1995 (Lovibond \& Lovibond, 1995). The items in the DASS-21 had been translated into Bahasa Indonesia and are commonly used in Indonesia. The DASS-21 consists of three components to measure symptoms of depression, anxiety, and stress. Overall, the DASS-21 consists of 21 items, and the strength of each item is measured by 4 Likert-scales. Reliability testing on this scale obtained internal consistency with a Cronbach's alpha 0.821.

Self-criticism. This variable was measured by the Forms of Self-Criticising/Attacking \& Self-Reassuring Scale (FSCRS). This scale was developed by Gilbert in 2004 (Baião, Gilbert, McEwan, \& Carvalho, 2015). Overall, this instrument aimed to measure self-criticism and self-assuring (Baião, Gilbert, McEwan, \& Carvalho, 2015), and is the only component of self-criticism which was used in this study. This scale consists of 14 items that measured selfincompetence and self-hatred. Each item was measured by 5 Likert-scales. This scale was previously used in Indonesian studies, but not commonly. Thus, before using this scale, the researchers translated the items into Bahasa Indonesia with guidance from professionals in psychology and English. After that, the researchers tested the readability of the items to college students from various disciplines. According to reliability testing, this scale had internal consistency with a Cronbach's alpha 0.765.

The Urge to Self-Injure. This variable was measured by the Alexian Brothers Urge to SelfInjure Scale (ABUSI) developed by Washburn in 2010 (Washburn, Juzwin, Styer, \& 
Aldridge, 2010). This scale was initially used to measure the urge to self-injure in clinical samples. This scale consists of 5 items which are measured by 7 Likert-scales. This scale had never been used in the Bahasa Indonesia version. Thus, the researchers conducted the translation process as before with FSCRS. A reliability test was performed on the items that had been translated. The reliability test on this scale obtained internal consistency with a Cronbach's alpha 0.838 .

\section{Results}

The mean of the urge to self-injure was higher in participants under 23 years old ( $\mathrm{n}=71, \mathrm{M}=$ 18.67) than above 23 years old $(n=47, M=16.89)$. The participants in this study reported that the function of self-injury behavior was more to regulate their negative feelings externally $(\mathrm{M}=3.64$, Std $=1.21)$. Therefore, self-injury was an attempt to express their anger, frustration, and other uncomfortable feelings, so that the internal tension could be reduced. There were two methods of self-injury reported by most of the participants: $47 \%$ of participants reported cutting their skin with sharp objects $(n=55)$ and $44 \%$ of participants reported banging their heads $(\mathrm{n}=52)$

According to the results of the bivariate correlation test, negative emotional symptoms, selfcriticism, and the urge to self-injure had a significant relationship with one another (see Table 1). The coefficient of correlation showed that negative emotional symptoms and self-criticism had a strong positive relationship $(\mathrm{r}=0.754, \mathrm{p}=0.000)$. This result indicated that the higher negative emotional symptoms, the higher the level of self-criticism. Each of the predictors significantly had positive and moderate strength correlation $(r>0.400, p=0.000)$ toward the intensity of the urge to self-injure.

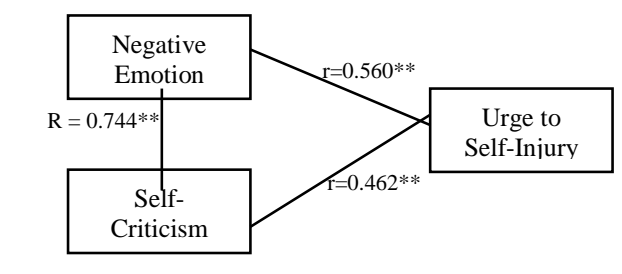

$* *$ significance correlation $p=0.000$, Correlation is significant at the 0.01 level (2-tailed)

Fig. 1. Correlation of Variables

According to the results of multiple linear regression analysis, both predictors simultaneously impacted on the urge to self-injure by 32 percent $\left(\mathrm{R}^{2}=0.318, \mathrm{p}=0.000\right)$. This result explained that both of the negative emotional symptoms and self-criticism made a considerable contribution to increasing the urge to self-injure. According to data analysis, negative emotional symptoms has higher contribution $\left(R^{2}=0.307, p=0.000\right)$ than self-criticism $\left(R^{2}=\right.$ $0.214, \mathrm{p}=0.000)$. 


\begin{tabular}{|c|c|c|c|}
\hline \multicolumn{4}{|c|}{ TABLE I. COEFFICIENT OF IMPACT } \\
\hline & $\boldsymbol{R}$ & $R^{2}$ & Std \\
\hline $\begin{array}{l}\text { (a) Negative } \\
\text { Emotion*** }\end{array}$ & 0.506 & 0.307 & 5.204 \\
\hline $\begin{array}{l}\text { (b) Self- } \\
\text { Criticism }^{* *}\end{array}$ & 0.462 & 0.214 & 5.590 \\
\hline (a) $x(b)^{* * *}$ & 0.564 & 0.318 & 5.209 \\
\hline
\end{tabular}

\section{Discussion}

A strong positive relationship between negative emotional symptoms and self-criticism $(\mathrm{r}=$ $0.754, \mathrm{p}=0.000$ ) shows that these variables are interrelated factors. The college students who injure themselves have low tolerance in terms of completing difficult tasks (Nock \& Mendes, 2008). They are quick to criticize themselves in difficult situations. Self-criticism has an association with increased negative affect and reduced positive affect (Mongrain \& Zuroff, 1995). Some studies argued that self-criticism can be a transdiagnostic process that has implications for various mental disorders, such as depression, anxiety, and stress (Andover, Pepper, Ryabchenko, Orrico, \& Gibb, 2005; McIntyre, Smith, \& Rimes, 2018; Mongrain \& Zuroff, 1995) or negative emotional symptoms. Conversely, the failure to deal with these kinds of negative emotional symptoms will lead the individual to further develop selfcriticism (Gilbert, 2000; Gilbert \& Irons, 2009).

Findings in this study accept the hypothesis that both negative emotional symptoms and selfcriticism have a significant influence on the intensity of urge to self-injure. The influence coefficient of these variables showed that both negative emotional symptoms and selfcriticism was constituted a significant variable in evoking the urge to self-injure in the college students. This is consistent with the result of the previous study which found that negative emotional symptoms and self-criticism were predictors that influenced the urge to self-injure (Richmond, Hasking, \& Meaney, 2017; Xavier, Gouveia, \& Cunha, 2016). Inability to regulate their negative emotions and to switch off thoughts of self-criticism will escalate the individual's urge to injure themselves. According to escape coping theory, the urge to selfinjure is aroused because of the students' desire to reduce the unbearable psychological distress immediately (Hack \& Martin, 2018; Williams, 2010). Self-injury was a temporary diversion switching attention from psychological pain to physical pain (Williams, 2010). Self-injury becomes the last attempt to escape from the uncomfortable condition. The college students who injured themselves not only hoped to escape from their negative emotions, but also from negative self-belief (Michelson \& Bhugra, 2012) through this behavior. Thus, this behavior is not only an effort to regulate emotions but also to punish themselves for perceived failure and purify the part of their self that they hate (Gratz \& Chapman, 2009; Connor, 1996; Himber, 1994; Klonsky, Muehlenkamp, Lewis, \& Walsh, 2011; Nock, 2009; Shearer, 1994; Zlotnick, Donaldson, Spirito, \& Pearlstein, 1997) due to high self-criticism. Feelings of relief after committing self-injury can be a positive reinforcement for the college students to generate the urge to repeat the same behavior in the future. 
The result, that participants under the age of 23 years old showed a greater urge to self-injure, is in line with previous studies that found the early onset of the emergence of self-injury behavior at between 14 and 24 years old (Klonsky, 2007; Laye-Gindhu \& Schonert-Reichl, 2005). In Indonesia, 18-22 is the usual age range of undergraduates. At this level, many individuals leave home for the first time, they face a new academic process, as a college student, whereby theyhave to be more independent in completing tasks compared to previous levels of education. They must deal with various demands, both internal (self-expectations) and external self (social expectations). In this phase, they are expected to be able to independently solve their problems, while in the previous life phase they still depended on their parents (Arnett, 2007; Arnett, Kloep, Hendry, \& Tanner, 2011).

Another predictor that may contribute to the emergence of self-injury behavior is the quality of interpersonal relationships. In the emerging adulthood period, peers become the main source of social support for college students, replacing the main source of support previously given by parents. In this transition period, they begin to develop separate identities from their parents, and enact their peer relationship as primary sources of support, value, and sense of belonging (Gilbert \& Irons, 2009; Wolfe \& Mash, 2006). The previous study in Indonesia found that self-injuring individuals tended to isolate themselves from the social environment (Maidah, 2013). Negative self-evaluation makes individuals try to reduce risk to get higher negative self-assessment and rejection from their environment. The college students who selfinjure develop a high self-focus (Williams, 2010). They become more focused and very sensitive to self-image and the reaction of their immediate social environment toward themselves (Gilbert \& Irons, 2009). Furthermore, they tend to express superficial emotions that can be accepted by their immediate peers and limit their deep relationships, so that they become vulnerable to feeling lonely (Hidayati \& Muthia, 2015). This condition is in contrast to the peer function itself, where the peers actually facilitate the problem-sharing and help individuals to adjust themselves. The quality of interpersonal relationships also becomes one of the agents that turn the urge into actual self-injury behavior (Xavier, Gouveia, \& Cunha, 2016).

\section{Conclusion}

The results of this study answered the researchers' questions about the impact of negative emotional symptoms and self-criticism on the intensity of an urge to self-injure. Negative emotional symptoms (depression, anxiety, and stress) and the level of self-criticism were interconnected. An increase in negative emotional symptoms would increase the level of selfcriticism, and vice versa. Simultaneously, these two variables have a significant influence on the intensity of the urge to self-injure in college students. Furthermore, other factors that might influence self-injury behavior are the quality of interpersonal relationships and personality. However, these two variables were not measured in this study.

Findings from this study can act as preliminary data to develop further research on self-injury behavior, especially in Indonesia. Results from two predictors toward the urge to self-injure 
should be considered in designing psychological interventions for college students to reduce self-injury. The focuses of psychological intervention may include strategies for coping with negative emotions and to switching away from thoughts of self-criticism. Findings from the current study can also be an input for educational institutions to create a positive learning climate so that the college students are provided with a support system during their academic process. In addition, educational institutions can educate their students about the negative effects of self-injury behavior, and provide psychological services as a response to this behavior in the college students.

\section{Suggestion for future research}

The current study had several shortcomings that could act as an input for improvement of further research. The first was that in this study the number of male participants was not comparable to female participants. The subsequent research is expected to expand the population of data collection to get a more representative comparison of participants (for example, sex, age, background). Looking at populations not limited to college students who live in Jabodetabek, would provide a broader picture of self-injury behavior in Indonesia. Secondly, the measuring instruments used in this study were not generally used in Indonesia, namely FSCRS and ABUSI. This might allow cultural bias to occur in completing in the instruments, such as language. In the process of translating the instruments, researchers only used the minimum sample size to conduct the reliability test. The instrument test in larger samples and wider populations in Indonesia is needed in the future. Thirdly, this study did not directly measure the frequency of self-injury behavior. In this research, many participants had difficulty remembering and calculating their specific number of self-injury behaviors, so the data obtained was not entirely accurate. In the next studies, live report-based measurement could be carried out to determine the intensity of behavior more accurately. The last shortcoming was the lack of data related to several variables associated with self-injury behavior, such as social relations and personality. It is also important to explore the function or benefit that individuals acquire through this behavior. These variables could be a focus of future study related to self-injury behavior and could provide additional information to conduct a more comprehensive behavior analysis.

\section{Acknowledgment}

The authors would like to thank Dr. Adriana Soekandar Ginanjar, M.S., Psychologist who helped us by providing input and support during the study preparation.

\section{References}

Andover, M. S., Pepper, C. M., Ryabchenko, K. A., Orrico, E. G., \& Gibb, B. E. (2005). Self-mutilation and symptoms of depression, anxiety, and borderline personality disorder. Suicide and Life-Threatening Behavior, 35(5), 581-591.

Arnett, J. J. (2007). Emerging adulthood: What is it, and what is it good for?. Child Development Perspectives, $1(2), 68-73$.

Arnett, J. J., Kloep, M., Hendry, B., \& Tanner, J. L. (2011). Debating emerging adulthood: Stage or process. Oxford: Oxford University Press. 
Baião, R., Gilbert, P., McEwan, K., \& Carvalho. (2015). Forms of self-criticising/attacking \& self-reassuring scale: Psychometric properties and normative study. Psychology and Psychotherapy: Theory, Research and Practice, 88(4), 438-452.

Baumeister, R. F. (1990). Suicide as escape from self. Psychological Review, 97(1), 90.

Baumeister, R. F. (1991). The self against itself: Escape or defeat. In R. C. Curtis (Ed.), The relational self: Theoretical convergences in psychoanalysis and social psychology (pp. 238-256). New York: Guilford.

Carvalho, C. B., Sousa, M., Motta, C. D., Pinto-Gouveia, J., Caldeira, S. N., Peixoto, E. B., Cabral, J., \& Feingstein, A. (2015). Paranoia in the general population: A revised version of the General Paranoia Scale for adults. Clinical Psychologist, 21(2), 125-134.

Connor, S. (1996). Postmodernist culture. Blackwell Publishers.

Favazza, A. R., DeRosear, L. \& Conterio, K. (1989). Self-mutilation and eating disorders. Suicide and LifeThreatening Behavior, 19(4), 352-361.

Gilbert, P. (1998). What is shame? Some core issues and controversies. In P. Gilbert and B. Andrews (eds.), Shame: Interpersonal Behavior, Psychopathology and Culture (pp. 3-38). New York: Oxford University Press.

Gilbert, P. (2000). The relationship of shame, social anxiety and depression: The role of the evaluation of social rank. Clinical Psychology \& Psychotherapy: An International Journal of Theory \& Practice, 7(3), 174189.

Gilbert, P., Clarke, M., Hempel, S., Miles, J. N., \& Irons, C. (2004). Criticizing and reassuring oneself: An exploration of forms, styles and reasons in female students. British Journal of Clinical Psychology, 43(1), 31-50.

Gilbert, P. \& Irons, C. (2009). Shame, self-criticism, and self-compassion in adolescence. In N. B. Allen and L. B. Sheeber (eds.), Adolescent emotional development and the emergence of depressive disorders (pp. 195-214), Cambridge: Cambridge University Press.

Glassman, L. H., Weierich, M. R., Hooley, J. M., Deliberto, T. L., \& Nock, M. K. (2007). Child maltreatment, non-suicidal self-injury, and the mediating role of self-criticism. Behaviour Research and Therapy, 45(10), 2483-2490.

Gratz, K. L. \& Chapman, A. L. (2009). Freedom from self-harm: Overcoming self-injury with skills from DBT and other treatments. Oakland, CA: New Harbinger Publications.

Hack, J. \& Martin, G. (2018). Expressed emotion, shame, and non-suicidal self-injury. International Journal of Environmental Research and Public Health, 15(5).

Hankin, B. L. \& Abela, J. R. (2011). Nonsuicidal self-injury in adolescence: Prospective rates and risk factors in a 2 1/2 year longitudinal study. Psychiatry Research, 186(1), 65-70.

Hewitt, P. L., Newton, J., Flett, G. L., \& Callander, L. (1997). Perfectionism and suicide ideation in adolescent psychiatric patients. Journal of Abnormal Child Psychology, 25(2), 95-101.

Hidayati, D. S. \& Muthia, C. M. (2015). Kesepian dan Keinginan Melukai Diri Sendiri Remaja. Psympathic: Jurnal Ilmiah Psikologi, 2(2), 185-198.

Himber, J. (1994). Blood rituals: Self-cutting in female psychiatric inpatients. Psychotherapy: Theory, Research, Practice, Training, 31(4), 620.

Hoff, E. R. \& Muehlenkamp, J. J. (2009). Nonsuicidal self-injury in college students: The role of perfectionism and rumination. Suicide and Life \& Threatening Behavior, 39(6), 576-587.

Hooley, J. M. \& St Germain, S. A. (2013). Borderline personality disorder. Hoboken, NJ: John Wiley and Sons. Hooley, J. M. \& St Germain, S. A. (2014). Nonsuicidal self-injury, pain, and self-criticism: Does changing selfworth change pain endurance in people who engage in self-injury? Clinical Psychological Science, 2(3), 297-305.

Izadinia, N., Amiri, M., Jahromi, R. G., \& Hamidi, S. (2010). A study of relationship between suicidal ideas, depression, anxiety, resiliency, daily stresses and mental health among Tehran university students. Procedia - Social and Behavioral Sciences, 5, 1615-1619.

Jacobson, C. M., \& Gould, M. (2007). The epidemiology and phenomenology of non-suicidal self-injurious behavior among adolescents: A critical review of the literature. Archives of Suicide Research, 11(2), 129147. 
Klonsky, E. D. (2007). Non-suicidal self-injury: An introduction. Journal of Clinical Psychology, 63(11), 10391043.

Klonsky, E. D. (2009). The functions of self-injury in young adults who cut themselves: Clarifying the evidence for affect-regulation. Psychiatry Research, 166(2-3), 260-268.

Klonsky, E. D. (2011). Non-suicidal self-injury in United States adults: prevalence, sociodemographics, topography and functions. Psychological Medicine, 41(9), 1981-1986.

Klonsky, E. D., \& Glenn, C. R. (2009). Assessing the functions of non-suicidal self-injury: Psychometric properties of the Inventory of Statements About Self-injury (ISAS). Journal of Psychopathology and Behavioral Assessment, 31(3), 215-219.

Klonsky, E. D., Muehlenkamp, J., Lewis, S. P., \& Walsh, B. (2011). Nonsuicidal Self-injury (Vol. 2). Cambridge, MA: Hogrefe Publishing.

Lovibond, P. F. \& Lovibond, S. H. (1995). The structure of negative emotional states: Comparison of the Depression Anxiety Stress Scales (DASS) with the Beck Depression and Anxiety Inventories. Behaviour Research and Therapy, 33(3), 335-343.

Maidah, D. (2013). Self-injury pada mahasiswa - Studi kasus pada mahasiswa pelaku self-injury. (Undergraduate's mini thesis). Universitas Negeri Semarang.

McIntyre, R., Smith, P., \& Rimes, K. A. (2018). The role of self-criticism in common mental health difficulties in students: A systematic review of prospective studies. Mental Health \& Prevention.

Michelson, D., \& Bhugra, D. (2012). Family environment, expressed emotion and adolescent self-harm: A review of conceptual, empirical, cross-cultural and clinical perspectives. International Review of Psychiatry, 24(2), 106-114. doi: 10.3109/09540261.2012.657613.

Mongrain, M., \& Zuroff, D. C. (1995). Motivational and affective correlates of dependency and selfcriticism. Personality and Individual Differences, 18(3), 347-354.

Muehlenkamp, J. J. (2005). Self-injurious behavior as a separate clinical syndrome. American Journal of Orthopsychiatry, 75(2), 324-333.

Muehlenkamp, J. J., \& Gutierrez, P. M. (2004). An investigation of differences between self-injurious behavior and suicide attempts in a sample of adolescents. Suicide and Life-Threatening Behavior, 34(1), 12-23.

Nixon, M. K. \& Cloutier, P. (2005). Ottawa Self-Injury Inventory. Victoria BC: University of British Columbia and Victoria.

Nock, M. K. (2009). Why do people hurt themselves? New insights into the nature and functions of selfinjury. Current Directions in Psychological Science, 18(2), 78-83.

Nock, M. K. (2010). Self-injury. Annual Review of Clinical Psychology, 6, 339-363.

Nock, M. K., \& Mendes, W. B. (2008). Physiological arousal, distress tolerance, and social problem-solving deficits among adolescent self-injurers. Journal of Consulting and Clinical Psychology, 76(1), 28.

Nock, M. K., \& Prinstein, M. J. (2004). A functional approach to the assessment of self-mutilative behavior. Journal of Consulting and Clinical Psychology, 72(5), 885.

O'Connor, R. C., Rasmussen, S., \& Hawton, K. (2010). Predicting depression, anxiety and self-harm in adolescents: The role of perfectionism and acute life stress. Behaviour Research and Therapy, 48(1), 5259.

Purington, A., \& Whitlock, J. (2010). Non-suicidal self-injury in the media. The Prevention Researcher, 17(1), $11-14$

Raza, A., Abbasi, N. U. H., Khurshid, M., \& Ansari, M. I. (2018). The relationship between depression, anxiety, stress, and self-harm among college students: A cross-sectional survey. Pakistan Armed Forces Medical Journal, 68(1), 137-42.

Richmond, S., Hasking, P., \& Meaney, R. (2017). Psychological distress and non-suicidal self-injury: the mediating roles of rumination, cognitive reappraisal, and expressive suppression. Archives of Suicide Research, 21(1), 62-72.

Ross, S., \& Heath, N. (2002). A study of the frequency of self-mutilation in a community sample of adolescents. Journal of Youth and Adolescence, 31(1), 67-77.

Shearer, S. L. (1994). Phenomenology of self-injury among inpatient women with boderline personality disorder. Journal of Nervous and Mental Disease. 
St Germain, S. A. \& Hooley, J. M. (2012). Direct and indirect forms of non-suicidal self-injury: Evidence for a distinction. Psychiatry Research, 197(1-2), 78-84.

Suyemoto, K. L. (1998). The functions of self-mutilation. Clinical Psychology Review, 18(5), 531-554.

Van Vliet, K., \& Kalnins, G. (2011). A compassion-focused approach to nonsuicidal self-injury. Journal of Mental Health Counseling, 33(4), 295-311.

Walsh, B. (2007). Clinical assessment of self-injury: A practical guide. Journal of Clinical Psychology, 63(11), 1057-1068.

Washburn, J. J., Juzwin, K. R., Styer, D. M., \& Aldridge, D. (2010). Measuring the urge to self-injure: Preliminary data from a clinical sample. Psychiatry Research, 178(3), 540-544.

Whitlock, J., Eckenrode, J., \& Silverman, D. (2006). Self-injurious behaviors in a college population. Pediatrics, 117(6), 1939-1948.

Whitlock, J., \& Knox, K. L. (2007). The relationship between self-injurious behavior and suicide in a young adult population. Archives of Pediatrics \& Adolescent Medicine, 161(7), 634-640.

Williams, D. (2010). Hurting to cope: Self-injurious behavior as an escape from self-focus. Undergraduate Review, 6(1), 120-129.

Williams, K. A., \& Bydalek, K. A. (2007). Adolescent self-mutilation: Diagnosis and treatment. Journal of Psychosocial Nursing and Mental Health Services, 45(12), 19-23.

Wolfe, D. A., \& Mash, E. J. (Eds.). (2006). Behavioral and emotional disorders in adolescents: Nature, assessment, and treatment. Guilford Press.

Xavier, A., Cunha, M., \& Pinto Gouveia, J. (2015). Deliberate self-harm in adolescence: The impact of childhood experiences, negative affect and fears of compassion. Revista de Psicopatología y Psicología Clínica, 20(1), 41-49.

Xavier, A., Gouveia, J. P., \& Cunha, M. (2016). Non-suicidal self-injury in adolescence: The role of shame, self-criticism and fear of self-compassion," In Child \& Youth Care Forum (Vol. 45, No. 4, pp. 571-586), Springer US.

Zlotnick, C., Donaldson, D., Spirito, A., \& Pearlstein, T. (1997). Affect regulation and suicide attempts in adolescent inpatients. Journal of the American Academy of Child \& Adolescent Psychiatry, 36(6), 793798. 